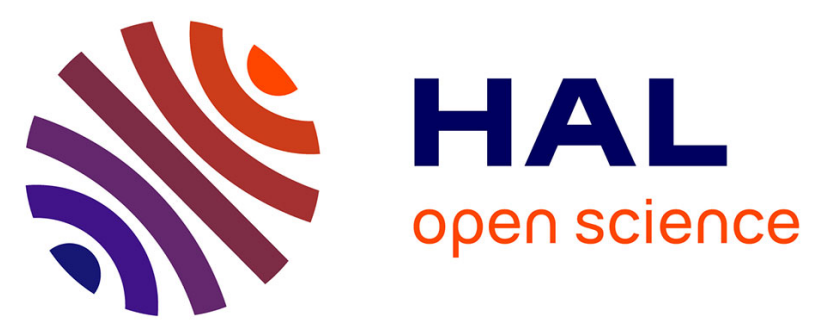

\title{
Neurally Adjusted Ventilatory Assist vs Pressure Support Ventilation for Noninvasive Ventilation During Acute Respiratory Failure
}

Pierre-Marie Bertrand, Emmanuel Futier, Yannaël Coisel, Stefan Matecki, Samir Jaber, Jean-Michel Constantin

\section{To cite this version:}

Pierre-Marie Bertrand, Emmanuel Futier, Yannaël Coisel, Stefan Matecki, Samir Jaber, et al.. Neurally Adjusted Ventilatory Assist vs Pressure Support Ventilation for Noninvasive Ventilation During Acute Respiratory Failure. Chest, 2013, 10.1378/chest.12-0424 . hal-02544955

\section{HAL Id: hal-02544955 \\ https://hal.umontpellier.fr/hal-02544955}

Submitted on 16 Apr 2020

HAL is a multi-disciplinary open access archive for the deposit and dissemination of scientific research documents, whether they are published or not. The documents may come from teaching and research institutions in France or abroad, or from public or private research centers.
L'archive ouverte pluridisciplinaire HAL, est destinée au dépôt et à la diffusion de documents scientifiques de niveau recherche, publiés ou non, émanant des établissements d'enseignement et de recherche français ou étrangers, des laboratoires publics ou privés. 


\title{
Neurally Adjusted Ventilatory Assist vs Pressure Support Ventilation for Noninvasive Ventilation During Acute Respiratory Failure
}

\author{
A Crossover Physiologic Study
}

\author{
Pierre-Marie Bertrand, MD; Emmanuel Futier, MD; Yannael Coisel, MD; \\ Stefan Matecki, MD, PhD; Samir Jaber, MD, PhD; and Jean-Michel Constantin, MD, PhD
}

\begin{abstract}
Background: Patient-ventilator asynchrony is common during noninvasive ventilation (NIV) with pressure support ventilation (PSV). We examined the effect of neurally adjusted ventilatory assist (NAVA) delivered through a facemask on synchronization in patients with acute respiratory failure (ARF).

Methods: This was a prospective, physiologic, crossover study of 13 patients with ARF (median $\mathrm{PaO}_{2} / \mathrm{FIO}_{2}, 196$ [interquartile range (IQR), 142-225]) given two 30-min trials of NIV with PSV and NAVA in random order. Diaphragm electrical activity (EAdi), neural inspiratory time (Tin), trigger delay (Td), asynchrony index (AI), arterial blood gas levels, and patient discomfort were recorded.

Results: There were significantly fewer asynchrony events during NAVA than during PSV (10 [IQR, 5-14] events vs 17 [IQR, 8-24] events, $P=.017)$, and the occurrence of severe asynchrony $(A I>10 \%)$ was also less under NAVA $(P=.027)$. Ineffective efforts and delayed cycling were significantly less with NAVA $(P<.05$ for both). NAVA was also associated with reduced Td $(0$ [IQR, 0-30] milliseconds vs 90 [IQR, 30-130] milliseconds, $P<.001)$ and inspiratory time in excess (10 [IQR, 0-28] milliseconds vs 125 [IQR, 20-312] milliseconds, $P<.001$ ), but Tin was similar under PSV and NAVA. The EAdi signal to its maximal value was higher during NAVA than during PSV $(P=.017)$. There were no significant differences in arterial blood gases or patient discomfort under PSV and NAVA.

Conclusion: In view of specific experimental conditions, our comparison of PSV and NAVA indicated that NAVA significantly reduced severe patient-ventilator asynchrony and resulted in similar improvements in gas exchange during NIV for ARF.

Trial registry: ClinicalTrials.gov; No.: NCT01426178; URL: www.clinicaltrials.gov.
\end{abstract}

Abbreviations: $\mathrm{AI}=$ asynchrony index; $\mathrm{ARF}=$ acute respiratory failure; EAdi = electrical activity of the diaphragm; EAdi $\max =$ electrical activity of the diaphragm signal to its maximal value; IQR = interquartile range; NAVA = neutrally adjusted ventilatory assist; NIV = noninvasive ventilation; PSV = pressure support ventilation; $\mathrm{Td}=$ trigger delay; TIexe $=$ inspiratory time in excess; TIn $=$ neural inspiratory time; $V_{T}=$ tidal volume; VTE $=$ expiratory tidal volume; $\mathrm{VTI}=$ inspiratory tidal volume

$\mathbf{N}$ oninvasive ventilation (NIV) is increasingly used as a life-support therapy to prevent intubation during acute respiratory failure (ARF).1,2 However, NIV failure is strongly associated with poor outcome. ${ }^{3}$

NIV usually refers to the use of pressure support ventilation (PSV) that seeks to synchronize ventilator insufflation in accordance with the patient's effort. ${ }^{4}$
Patient-ventilator synchronization is critical for reducing the work of breathing and for successful NIV. ${ }^{5}$ Although PSV allows the patient to influence the breathing pattern, ventilator cycling criteria may worsen the patient-ventilator interaction, and severe asynchronies occur in up to $43 \%$ of patients undergoing NIV for ARF. 6 
Neurally adjusted ventilatory assist (NAVA) is an assisted ventilatory mode that delivers a pressure proportional to the integral of the electrical activity of the diaphragm (EAdi). ${ }^{7}$ Ventilator support begins when the neural drive to the diaphragm begins to increase, and pressure is cycled off when the respiratory centers end the EAdi. ${ }^{8}$ Compared with PSV, NAVA can reduce patient-ventilator asynchrony during invasive mechanical ventilation. ${ }^{9,10}$ To date, however, few data are available in patients receiving NIV for ARF.

The aim of the present physiologic, prospective, crossover study was to compare the short-term effects of NAVA and PSV in delivering NIV with a facemask on patient-ventilator synchronization. We hypothesized that, compared with PSV, NAVA would reduce severe patient-ventilator asynchrony during NIV in selected hypoxemic patients with ARF.

\section{Materials AND Methods}

This study was performed in the ICU of the Estaing Hospital (University of Clermont-Ferrand, France) from July 2011 to September 2011. The Institutional Review Board (Comité de Protection des Personnes Sud-Est I, Clermont-Ferrand, France) approved the protocol (reference number 2010-A01197-32), and each patient or next of kin provided written informed consent. This study followed CONSORT recommendations regarding the report of randomized trials. ${ }^{11}$

\section{Study Population and Experimental Protocol}

All consecutive patients with ARF admitted to the ICU were eligible if they had at least two of the following five criteria for initiation of NIV6: (1) worsening of dyspnea in the previous 10 days in the presence of chronic respiratory failure, $(2)$ respiratory rate $>25$ cycles/min, (3) respiratory acidosis with $\mathrm{pH}<7.35$, (4) $\mathrm{PaCO}_{2}>50 \mathrm{~mm} \mathrm{Hg}$, and (5) $\mathrm{PaO}_{2}<50 \mathrm{~mm} \mathrm{Hg}$. Patients with any contraindication for the insertion of a nasogastric tube or any classic contraindication to NIV were excluded. ${ }^{2}$

A Servo-I ventilator (MAQUET Gmbh \& Co KG), using NIV software to compensate for air leaks, was used to deliver PSV, and a dedicated module and software were used for NAVA. EAdi

Manuscript received February 15, 2012; revision accepted May 2, 2012.

Affiliations: From the Department of Anesthesiology and Critical Care (Drs Bertrand, Constantin, and Futier), Estaing Hospital, University Hospital of Clermont-Ferrand, Clermont-Ferrand; the Department of Anesthesiology and Critical Care (SAR B) (Drs Coisel and Jaber), Saint Eloi Hospital, University Hospital of Montpellier; and the Institut National de la Santé et de la Recherche Médicale (INSERM) (Drs Matecki and Jaber), Unit U1046, University of Montpellier, Montpellier, France.

Funding/Support: The authors have reported to CHEST that no funding was received for this study.

Correspondence to: Emmanuel Futier, MD, Département d'Anesthésie et Réanimation (DAR), Hôpital Estaing, Centre Hospitalier Universitaire de Clermont-Ferrand, 1 place Lucie Aubrac, 63000 Clermont-Ferrand cedex 1, France; e-mail: efutier@ chu-clermontferrand.fr

(c) 2013 American College of Chest Physicians. Reproduction of this article is prohibited without written permission from the American College of Chest Physicians. See online for more details. DOI: 10.1378/chest.12-0424 was obtained through a nasogastric tube with a multiple array of electrodes placed at the distal end (EAdi catheter; MAQUET Gmbh \& Co KG). ${ }^{12}$ Correct positioning was established by use of dedicated software, ${ }^{13}$ and continuous gastric emptying was performed to limit gastric air insufflation, in line with standard practice during NIV in our institution.

All patients were examined in the semirecumbent position, and sedatives were not given during the measurements. After enrollment, each patient underwent two 30-min trials in random order and separated by a 30 -min rest period. ${ }^{14}$ In each mode, NIV was applied using a nonvented full facemask (ResMed) that was fitted tight to the face to avoid air leaks, focusing on leaks around the nasogastric tube. Pressure support and NAVA levels were adjusted to achieve a tidal volume (VT) of 6 to $8 \mathrm{~mL} / \mathrm{kg}$ of ideal body weight. In the PSV mode, flow-trigger sensitivity was adjusted to the lowest possible level that allowed detection of minimal inspiratory effort and avoided autotriggering. ${ }^{15,16}$ The EAdi trigger was set to a predetermined default value of $0.5 \mu \mathrm{V}$. In each mode, the airway pressure limit was set at $25 \mathrm{~cm} \mathrm{H}_{2} \mathrm{O} .{ }^{17}$ The physician set the positive end-expiratory pressure to 5 to $10 \mathrm{~cm} \mathrm{H}_{2} \mathrm{O}$ and the $\mathrm{FIO}_{2}$ to the level needed to reach a peripheral oxygen saturation of at least $92 \%$ and maintained these settings throughout the experiment. The fastest rate of pressurization and an expiratory trigger threshold of $30 \%$ of peak inspiratory flow were used in PSV. A fixed cycle-off value of $70 \%$ of peak EAdi was set in NAVA.

\section{Data Acquisition and Measurements}

On admission, demographic data, cause of ARF, Sequential Organ Failure Assessment (SOFA) score, and standard hemodynamics and arterial blood gas (obtained from a radial artery catheter) were recorded. Arterial blood gas analysis (GEM Premier 3000 analyzer; Instrumentation Laboratory) was performed at the end of each ventilation period. Peripheral oxygen saturation was measured continuously using pulse oximetry.

Respiratory parameters (airway pressure and flow, inspiratory VT [VTI], expiratory Vt [VTE], and respiratory rate) and EAdi were acquired from the ventilator through a RS232 interface at a sampling rate of $100 \mathrm{~Hz}$, and were recorded using dedicated software (Servo-tracker V3.6.2; MAQUET Gmbh \& Co KG). After stabilization, a 5-min period of each NIV trial was recorded and manually analyzed offline. ${ }^{15}$ The recordings were excluded if the EAdi signal was lost or if the ventilator automatically returned to PSV. In each trial, patient-ventilator asynchronies (ineffective efforts, autotriggering, premature cycling, delayed cycling, and double triggering) were determined on EAdi, airway pressure, and flow signal.6,18 The number of each type of asynchrony, defined as the number of events per minute, was determined for each recording period by two investigators (S. J. and J. M. C.) who were blinded to all analyzed tracings. The asynchrony index (AI), in percentage, was calculated as described previously, ${ }^{6,18}$ and an AI $>10 \%$ was considered severe asynchrony. ${ }^{18}$ Time parameters were determined from the EAdi and flow signals. ${ }^{6}$ The neural inspiratory time (TIn), in milliseconds, was defined as the time from the beginning of the EAdi signal to its maximal value (EAdi max), in microvolts. The trigger delay $(\mathrm{Td})$, in milliseconds, was defined as the time from the beginning of the EAdi signal to the beginning of the inspiratory flow. The inspiratory time in excess (TIexe), in milliseconds, was defined as the difference between the ventilator inspiratory pressurization time and the TIn. Leaks at the mask were computed using the equation, Leaks $(\%)=(\mathrm{VTI}-\mathrm{VTE}) / \mathrm{VTI} \times 100$, and were averaged over the recording period. Each patient reported the intensity of respiratory discomfort immediately after the end of each NIV trial by use of a Visually Enlarged Numerical Rating Scale (from 0 [no discomfort] to 10 [maximal imaginable discomfort]). ${ }^{19}$ 


\section{Statistical Analysis}

The primary end point was the difference in the AI obtained by PSV and NAVA. Power analysis indicated that a sample size of 12 was needed to demonstrate a $20 \%$ reduction in the AI between PSV and NAVA modes, with $\alpha$ and $\beta$ risks of 0.05 and 0.20 , respectively. The secondary end points were differences in each type of patient-ventilator asynchrony, patients with AI $>10 \%$, time parameters (TIn, EAdi max, TIexe, Td), and oxygenation.

The Kolmogorov-Smirnov test was used to assess normality. Normally distributed data are expressed as mean \pm SD and nonnormally distributed data are expressed as medians and interquartile range (IQR). Qualitative data are presented as absolute values or number of events (\%). Data were analyzed using the paired Student $t$ test or the Kruskal-Wallis $\mathrm{H}$ test, as appropriate. Post hoc analyses were performed with the Bonferroni correction when appropriate. A $P$ value $<.05$ was considered significant. Data were analyzed using SEM software (version 2.0; Centre Jean Perrin). ${ }^{20}$

\section{RESULTS}

Sixteen consecutive patients with ARF were enrolled initially. Three of these patients were excluded, two because a worsening of ARF required tracheal intubation, and one because of an inappropriate EAdi signal. A total of 13 patients completed the study protocol (Table 1). There was no patient with COPD. On admission, all patients needed oxygen therapy (mean $\mathrm{FIO}_{2}, 50 \% \pm 26 \%$ ).

Table 2 shows the ventilatory settings under PSV and NAVA. No relevant clinical problems occurred during any procedure, and none of the trials was stopped prematurely. During NAVA, no recording was excluded because of automatic reversion to PSV. The mean level of pressure support in PSV was $7 \pm 2 \mathrm{~cm} \mathrm{H}_{2} \mathrm{O}$, and the NAVA gain level was $0.6 \mathrm{~cm} \mathrm{H}_{2} \mathrm{O} / \mu \mathrm{V}$ (IQR, $0.3-0.8)$. There were no significant differences between the two NIV trials in airway pressure, expired TV, or positive end-expiratory pressure (Table 3 ). There was also no difference in the magnitude of leaks between the two NIV trials (12.6\% [IQR, 7-17] vs $14.2 \%$ [IQR, $6-19], P=.16$, during NAVA and PSV, respectively).

Table 3 shows the respiratory parameters and patient-ventilator asynchrony for the two NIV trials. Ineffective efforts and delayed cycling were the most common forms of asynchronies, and these were significantly more common under PSV (Table 3 ). There were no differences in autotriggering, double triggering, or premature cycling. The EAdi max, $\mathrm{Td}$, and TIexe were significantly lower during NAVA than during PSV (Table 3).

The AI was $60 \% \pm 30 \%$ lower during NAVA than during PSV (Fig 1). In addition, the number of patients with severe asynchrony (AI > 10\%) was significantly higher during PSV than during NAVA $(48 \%$ vs $8 \%$, $P=.027)$. There were also fewer total asynchronies during NAVA than during PSV (10 [IQR, 5-14] events vs 17 [IQR, 8-24] events, $P=.017$ ) (Fig 2).

Finally, Table 4 shows the arterial blood gases and hemodynamics during PSV and NAVA. Compared with baseline, $\mathrm{PaO}_{2} / \mathrm{FIO}_{2}$ was significantly higher during each NIV trial $(P=.029$ during PSV vs baseline and $P=.001$ during NAVA vs baseline) (Tables 1,4 ), but there was no significant difference during PSV and NAVA $(P=.62)$ (Table 4$)$. In addition, patients reported no significant differences in the intensity of respiratory discomfort during PSV and NAVA (PSV, 5 [IQR, 4-6]; NAVA, 7 [IQR, 5-8]; $P=.15$ ).

\section{Discussion}

With respect to specific experimental conditions, the results of the current study indicate that the use of NAVA instead of PSV for NIV in patients with ARF improves patient-ventilator interaction. In particular,

Table 1-Main Clinical Characteristics and Gas Exchange Parameters of the 13 Study Patients With Acute Respiratory Failure

\begin{tabular}{|c|c|c|c|c|c|c|c|c|}
\hline Patient No. & Cause of ARF & Age, y & Sex & $\mathrm{PaO}_{2} / \mathrm{FIO}_{2}$ Ratio & $\mathrm{PaCO}_{2}, \mathrm{~mm} \mathrm{Hg}$ & $\mathrm{pH}$ & $\mathrm{RR}, \mathrm{c} / \mathrm{min}$ & SOFA Score \\
\hline 1 & Postextubation & 58 & $\mathrm{M}$ & 185 & 35 & 7,51 & 34 & 2 \\
\hline 2 & Postextubation & 83 & $\mathrm{~F}$ & 218 & 35 & 7,45 & 27 & 2 \\
\hline 3 & Postextubation & 73 & $\mathrm{~F}$ & 84 & 41 & 7,39 & 34 & 4 \\
\hline 4 & Pneumonia & 73 & $\mathrm{~F}$ & 48 & 42 & 7,43 & 35 & 4 \\
\hline 5 & Pneumonia & 43 & $\mathrm{~F}$ & 43 & 37 & 7,45 & 37 & 3 \\
\hline 6 & Thoracic trauma & 59 & M & 275 & 39 & 7,48 & 28 & 3 \\
\hline 7 & Pneumonia & 79 & M & 235 & 38 & 7,46 & 30 & 6 \\
\hline 8 & Pneumonia & 64 & $\mathrm{M}$ & 196 & 28 & 7,55 & 30 & 6 \\
\hline 9 & Pneumonia & 81 & $\mathrm{~F}$ & 212 & 41 & 7,37 & 32 & 8 \\
\hline 10 & Pneumonia & 76 & $\mathrm{~F}$ & 142 & 28 & 7,44 & 34 & 2 \\
\hline 11 & Pneumonia & 66 & M & 226 & 40 & 7,44 & 30 & 3 \\
\hline 12 & Postextubation & 71 & $\mathrm{M}$ & 225 & 30 & 7,48 & 30 & 3 \\
\hline 13 & Postextubation & 43 & $\mathrm{~F}$ & 183 & 35 & 7,49 & 37 & 3 \\
\hline$\ldots$ & $\ldots$ & $67 \pm 12^{a}$ & $\ldots$ & $196(142-225)$ & $37(35-40)$ & $7.45(7.44-7.48)$ & $32 \pm 3$ & $3(3-4)$ \\
\hline
\end{tabular}

$\mathrm{ARF}=$ acute respiratory failure; $\mathrm{F}=$ female; $\mathrm{M}=$ male; $\mathrm{RR}=$ respiratory rate; $\mathrm{SOFA}=$ Sequential Organ Failure Assessment.

aData are presented as mean \pm SD or as median (interquartile range), according to their distribution. 
Table 2-Ventilator Settings in PSV and NAVA

\begin{tabular}{lc}
\hline \hline Ventilator Setting & Unit \\
\hline $\mathrm{FIO}_{2}$ & $0.4 \pm 0.1$ \\
$\mathrm{PEEP}$ level, $\mathrm{cm} \mathrm{H}_{2} \mathrm{O}$ & $6(5-7)$ \\
Inspiratory trigger & 1 \\
$\quad$ PSV, AU & 0.5 \\
$\quad \mathrm{NAVA}, \mu \mathrm{V}$ & \\
Expiratory trigger & $25-30$ \\
PSV, \% of maximal peak flow value & 30 \\
NAVA, \% of maximal peak EAdi value & $100-150$ \\
Pressurization slope, ms & $7 \pm 2$ \\
Pressure support level in PSV, cm $\mathrm{H}_{2} \mathrm{O}$ & $0.6(0.3-0.8)$ \\
NAVA gain level, cm $\mathrm{H}_{2} \mathrm{O} / \mu \mathrm{V}$ & \\
\hline Data are presented as absolute value, mean $\pm \mathrm{SD}$, or median (inter- & \\
quartile range) according to their distribution. AU = arbitrary unit; \\
EAdi = electrical activity of the diaphragm; NAVA = neurally adjusted \\
ventilatory assist; PEEP = positive end-expiratory pressure; PSV = pres- \\
sure support ventilation.
\end{tabular}

NAVA delivered through a facemask improved patientventilator interaction by reducing the total number of asynchrony events, severe patient-ventilator asynchrony ( $\mathrm{AI}>10 \%)$, the $\mathrm{Td}$, and Tiexe.

Our results agree with those of previous studies that showed that NAVA can improve patient-ventilator synchrony during NIV both in healthy subjects ${ }^{21}$ and in patients with postextubation failure. ${ }^{22}$ In contrast to previous studies, which used helmets, we used a facemask because facemasks are more common during acute clinical applications of NIV. ${ }^{2}$ In addition, use of a helmet is less efficient than use of a facemask in decreasing inspiratory effort and muscle unloading ${ }^{23}$ and is associated with greater patient-ventilator asynchrony during NIV. ${ }^{24}$ This might have led to an overestimate of the benefits of NAVA in a previous study by Cammarota et al,,$^{22}$ in which a severe AI $(>10 \%)$ was documented in an average of $80 \%$ of patients during each PSV trial.

The most remarkable difference between NAVA and PSV was the reduction in the number of patientventilator asynchrony events, especially ineffective efforts. Ineffective triggering, in which the patient's inspiratory effort fails to trigger the ventilator, is common during NIV ${ }^{6}$ and has been reported to increase the work of breathing. ${ }^{15}$ It is unlikely that excessive levels of assistance and leaks, which have been identified as important contributors to ineffective efforts, ${ }^{15,25}$ can explain our results. Indeed, we adjusted PSV levels to achieve a VT of 6 to $8 \mathrm{~mL} / \mathrm{kg}$, which is believed to limit overassistance. ${ }^{26}$ Moreover, because similar levels of airway pressure and TV were achieved during NAVA and PSV (Table 3), the levels of assistance were presumably equivalent. ${ }^{15}$ Interestingly, we also found that the Td was shorter during NAVA than during PSV. A dedicated NIV algorithm could correct for possible negative effects of air leaks on $\mathrm{Td}$ and pressurization, ${ }^{14,27}$ but a significant pneumatic signal is needed to initiate ventilator support in PSV, and a neural respiratory drive to the diaphragm is used in NAVA. ${ }^{8}$ Thus, our data are consistent with those of a recent study of intubated patients, ${ }^{9}$ although the use of an endotracheal tube does not allow direct comparison.

In contrast to previous data using helmets, ${ }^{22}$ our results indicated that delayed cycling and Tiexe were both better with NAVA and that TIn was unchanged. The delivered pressure under NAVA is closely synchronized with diaphragmatic activity, ${ }^{7}$ but under

Table 3-Respiratory Parameters and Patient-Ventilator Asynchrony During PSV and NAVA

\begin{tabular}{|c|c|c|c|}
\hline \multirow[b]{2}{*}{ Parameters and Asynchrony } & \multicolumn{2}{|c|}{ NIV Trial } & \multirow[b]{2}{*}{$P$ Value } \\
\hline & $\operatorname{PSV}(n=13)$ & $\operatorname{NAVA}(\mathrm{n}=13)$ & \\
\hline \multicolumn{4}{|l|}{ Respiratory parameters } \\
\hline Pmax, $\mathrm{cm} \mathrm{H}_{2} \mathrm{O}$ & $12.1(11.0-13.2)$ & $12.6(11.3-13.6)$ & .21 \\
\hline Pmin, $\mathrm{cm} \mathrm{H}_{2} \mathrm{O}$ & $4.4(4.1-6.5)$ & $4.9(4.4-5.8)$ & .18 \\
\hline \multicolumn{4}{|l|}{ VTE } \\
\hline $\mathrm{mL}$ & $515(410-593)$ & $498(421-663)$ & .06 \\
\hline $\mathrm{mL} / \mathrm{kg}$ & $8(6-8)$ & $8(7-8)$ & .08 \\
\hline PEEP, $\mathrm{cm} \mathrm{H}_{2} \mathrm{O}$ & $6(5-7)$ & $6(5-7)$ & .35 \\
\hline EAdi $\max , \mu \mathrm{V}$ & $10.6(8.1-18.8)$ & $11.9(10.0-15.1)$ & .017 \\
\hline TIn, ms & $880(770-1,140)$ & $870(770-1,055)$ & .63 \\
\hline $\mathrm{Td}$ & $90(30-130)$ & $0(0-30)$ & $<.001$ \\
\hline Tiexe, ms & $125(20-312)$ & $10(0-28)$ & $<.001$ \\
\hline \multicolumn{4}{|l|}{ Asynchrony, n/min } \\
\hline Ineffective efforts & $0.4(0.2-0.6)$ & $0.0(0.0-0.0)$ & .008 \\
\hline Autotriggering & $0.2(0.0-0.6)$ & $0.0(0.0-0.2)$ & .08 \\
\hline Double triggering & $0.2(0.0-0.2)$ & $0.06(0.0-0.4)$ & .10 \\
\hline Delayed cycling & $0.8(0.2-1.6)$ & $0.2(0.0-0.4)$ & .028 \\
\hline Premature cycling & $0.6(0.3-1.0)$ & $0.6(0.15-1.2)$ & .73 \\
\hline
\end{tabular}

Data are presented as median (interquartile range). NIV = noninvasive ventilation; Pmax = maximal airway pressure; Pmin = minimal airway pressure; $\mathrm{Td}=$ trigger delay; TIexe $=$ inspiratory time in excess; $\mathrm{TIn}=$ neural inspiratory time; VTE $=$ expired tidal volume. See Table 2 for expansion of other abbreviations. 


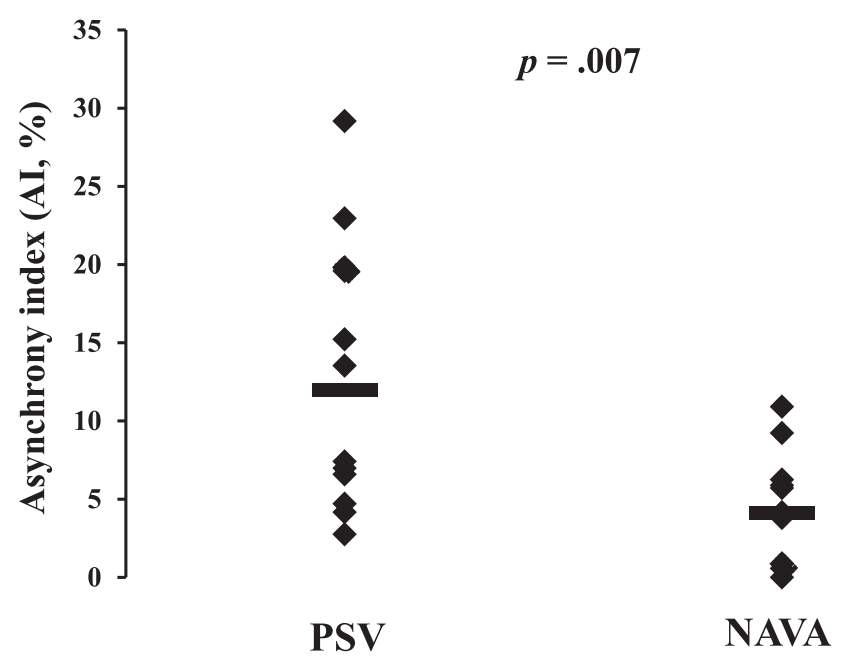

FIGURE 1. Individual values of the AI during PSV and NAVA. Black bars indicate the mean AI index during each noninvasive ventilation trial. There was a significant $(P=.007)$ difference between PSV and NAVA. An AI $>10 \%$ is considered severe asynchrony. $\mathrm{AI}=$ asynchrony index; NAVA = neutrally adjusted ventilatory assist; $\mathrm{PSV}=$ pressure support ventilation.

PSV, the end of the ventilator's inflation cycle does not necessary match the end of the patient's inspiratory effort. ${ }^{16}$ It should be noted, however, that Tiexe remains under NAVA, because the ventilator cyclingoff criterion induces an inherent delay between the end of the Tin and the end of the assistance delivered. ${ }^{9}$ Prolonged mechanical inflation beyond the Tin can promote overassistance, which, in turn, downregulates respiratory center activity ${ }^{16}$ and increases the work of breathing. ${ }^{28}$

EAdi max was higher under NAVA than under PSV, although peak pressure values and VT were not different between the two modes. This is contrary to the findings of previous studies of NIV. ${ }^{22}$ These differences may be due to the use of different types of
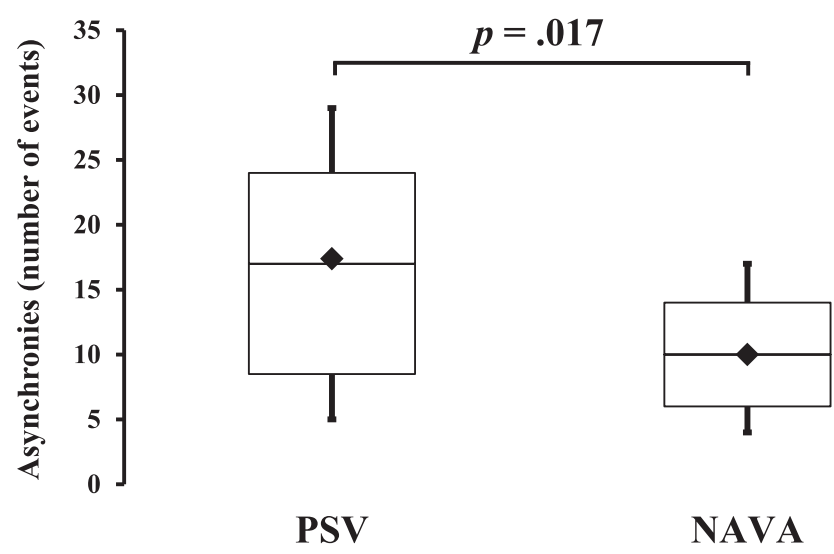

FIGURE 2. Total number of asynchronies during PSV and NAVA. Data are presented as median (horizontal line within the box), interquartile range (upper and lower edges of the boxes), maximum and minimum (upper and lower bars), and means ( within the boxes). See Figure 1 legend for expansion of abbreviations. interfaces and/or different patient selection criteria. Indeed, some previous studies examined patients who were on invasive ventilation for variable times, and this could have led to ventilator-induced diaphragmatic dysfunction that affected diaphragmatic effort in certain patients..$^{29,30}$ Beck et al ${ }^{31}$ emphasized that EAdi accurately reflects changes in phrenic nerve activity and global diaphragm activation (ie, respiratory drive) in patients with ARF, and that excessive assistance may be associated with a progressive neuromechanical uncoupling. ${ }^{31}$ Nevertheless, whether the use of NAVA can improve neuromechanical coupling of the diaphragm remained to determine.

Although NAVA requires the use of a nasogastric tube, which is usually not necessary for noninvasive PSV, our findings may be clinically relevant for patients with obstructive airway disease, whose Tiexe and overinflation can exacerbate dynamic hyperinflation. NIV demonstrated good efficacy in reducing the risk of invasive ventilation and mortality during acute exacerbation of COPD, ${ }^{32}$ but patient-ventilator asynchrony may reduce NIV success. ${ }^{6}$ NAVA may also represent an attractive alternative to PSV when applying NIV for treatment of postoperative $\mathrm{ARF}^{33}$ in particular after abdominal surgery, where the use of a nasogastric tube remains a common practice. Further well-powered and controlled trials are needed to better clarify the role of NAVA in these specific conditions.

The present study had several limitations. First, this was a physiologic study and was not designed to document patient outcome. Second, although our ventilator settings reflect usual clinical practice, our results should not be extrapolated outside this range of settings. Optimal NAVA level remains uncertain, ${ }^{34,35}$ and extension of our results to different clinical conditions requires further study. In addition, because the optimal flow cycling-off level may vary among individuals, ${ }^{36}$ the use of fixed, rather than individually optimized, criteria for expiratory trigger with PSV ( $25 \%-30 \%$ of peak inspiratory flow) could have led to

Table 4-Arterial Blood Gases and Hemodynamics During PSV and NAVA

\begin{tabular}{lccc}
\hline \hline Parameter & PSV $(\mathrm{n}=13)$ & NAVA $(\mathrm{n}=13)$ & P Value \\
\hline $\mathrm{pH}$ & $7.46(7.42-7.49)$ & $7.46(7.41-7.48)$ & .74 \\
$\mathrm{PaO}_{2} / \mathrm{FIO}_{2}$ & $287(201-346)$ & $311(245-347)$ & .62 \\
$\mathrm{PaCO}_{2}, \mathrm{~mm} \mathrm{Hg}$ & $39(37-40)$ & $36(34-38)$ & .15 \\
$\mathrm{HCO}_{3}{ }^{-}, \mathrm{mmol} / \mathrm{L}$ & $26(25-27)$ & $26(25-28)$ & .66 \\
$\mathrm{SaO}_{2}, \%$ & $98(97-99)$ & $98(97-99)$ & .61 \\
$\mathrm{MAP}, \mathrm{mm} \mathrm{Hg}$ & $93 \pm 11$ & $92 \pm 17$ & .95 \\
$\mathrm{HR}$, beats/min & $85 \pm 16$ & $88 \pm 14$ & .74 \\
\hline
\end{tabular}

Data are presented as mean \pm SD or median (interquartile range) according to their distribution. $\mathrm{HCO}_{3}{ }^{-}=$serum bicarbonate; $\mathrm{HR}=$ heart rate; $\mathrm{MAP}=$ mean arterial pressure; $\mathrm{SaO}_{2}=$ arterial saturation in oxygen . See Table 2 for expansion of other abbreviations. 
overestimation of the difference between NAVA and PSV. Third, there was no patient with known COPD in the study population. A recent study demonstrated, however, that NAVA improved patient-ventilator interaction in intubated patients with COPD relative to that provided by PSV, especially when high ventilatory assist is used. ${ }^{10}$ Nevertheless, because COPD is somewhat specific, it is uncertain whether our results can be extended to this population. Fourth, as reported previously, we used a visual numeric rating scale rather than a visual analog scale to assess patient discomfort during NIV. Nevertheless, neither psychometric properties of self-report scales for patient discomfort during NIV, such as validity and performance, nor comparison between them, has been performed in this setting.

In conclusion, based on our specific experimental conditions, we found that, compared with PSV, NAVA limits severe patient-ventilator asynchrony and results in similar improvement in gas exchange during NIV in patients with ARF. Further studies are needed to determine whether the use of NAVA during NIV can improve patient outcome.

\section{ACKNOWLEDGMENTS}

Author contributions: Drs Bertrand, Futier, and Constantin are guarantors of the paper and take responsibility for the integrity of the work as a whole, from inception to published article.

Dr Bertrand: contributed to the study design and protocol and recording and analysis of the data.

Dr Futier: contributed to the study design and protocol and writing and revision of the manuscript.

Dr Coisel: contributed to the study design and protocol and writing and revision of the manuscript.

Dr Matecki: contributed to the study design and protocol and writing and revision of the manuscript.

Dr Jaber: contributed to the study design and protocol, recording and analysis of the data, and writing and revision of the manuscript. Dr Constantin: contributed to the study design and protocol and recording and analysis of the data.

Financial/nonfinancial disclosures: The authors have reported to CHEST the following conflicts of interest: Dr Jaber was a consultant for Drager France Company and a consultant for MAQUET Gmbh \& Co KG. Drs Bertrand, Futier, Coisel, Matecki, and Constantin have reported that no potential conflicts of interest exist with any companies/organizations whose products or services may be discussed in this article.

Other contributions: The authors are grateful to Fabrice Kwiatkowski (Department of Statistics, centre Jean Perrin, Clermont-Ferrand, France), who performed statistical analysis, and to MAQUET Gmbh \& Co KG for providing the ventilator and EAdi catheters used in the study. This work was performed at the Intensive Unit, Estaing Hospital, University Hospital of Clermont-Ferrand, Clermont-Ferrand, France.

\section{REFERENCES}

1. Hill NS, Brennan J, Garpestad E, Nava S. Noninvasive ventilation in acute respiratory failure. Crit Care Med. 2007; 35(10):2402-2407.

2. Nava $S$, Hill N. Non-invasive ventilation in acute respiratory failure. Lancet. 2009;374(9685):250-259.
3. Ferrer M, Esquinas A, Leon M, Gonzalez G, Alarcon A, Torres A. Noninvasive ventilation in severe hypoxemic respiratory failure: a randomized clinical trial. Am J Respir Crit Care Med. 2003;168(12):1438-1444.

4. L'Her E, Deye N, Lellouche F, et al. Physiologic effects of noninvasive ventilation during acute lung injury. Am J Respir Crit Care Med. 2005;172(9):1112-1118.

5. Tobin MJ, Jubran A, Laghi F. Patient-ventilator interaction. Am J Respir Crit Care Med. 2001;163(5):1059-1063.

6. Vignaux L, Vargas F, Roeseler J, et al. Patient-ventilator asynchrony during non-invasive ventilation for acute respiratory failure: a multicenter study. Intensive Care Med. 2009;35(5): 840-846.

7. Sinderby C, Navalesi P, Beck J, et al. Neural control of mechanical ventilation in respiratory failure. Nat Med. 1999;5(12): 1433-1436.

8. Sinderby C, Beck J, Spahija J, et al. Inspiratory muscle unloading by neurally adjusted ventilatory assist during maximal inspiratory efforts in healthy subjects. Chest. 2007;131(3):711-717.

9. Piquilloud L, Vignaux L, Bialais E, et al. Neurally adjusted ventilatory assist improves patient-ventilator interaction. Intensive Care Med. 2011;37(2):263-271.

10. Spahija J, de Marchie M, Albert M, et al. Patient-ventilator interaction during pressure support ventilation and neurally adjusted ventilatory assist. Crit Care Med. 2010;38(2):518-526.

11. Schulz KF, Altman DG, Moher D; CONSORT Group. CONSORT 2010 statement: updated guidelines for reporting parallel group randomised trials. BMJ. 2010;340:c332.

12. Sinderby CA, Beck JC, Lindström LH, Grassino AE. Enhancement of signal quality in esophageal recordings of diaphragm EMG. J Appl Physiol. 1997;82(4):1370-1377.

13. Barwing J, Ambold M, Linden N, Quintel M, Moerer O. Evaluation of the catheter positioning for neurally adjusted ventilatory assist. Intensive Care Med. 2009;35(10):1809-1814.

14. Vignaux L, Tassaux D, Carteaux G, et al. Performance of noninvasive ventilation algorithms on ICU ventilators during pressure support: a clinical study. Intensive Care Med. 2010; 36(12):2053-2059.

15. Colombo D, Cammarota G, Bergamaschi V, De Lucia M, Corte FD, Navalesi P. Physiologic response to varying levels of pressure support and neurally adjusted ventilatory assist in patients with acute respiratory failure. Intensive Care Med. 2008;34(11):2010-2018.

16. Terzi N, Pelieu I, Guittet L, et al. Neurally adjusted ventilatory assist in patients recovering spontaneous breathing after acute respiratory distress syndrome: physiological evaluation. Crit Care Med. 2010;38(9):1830-1837.

17. Futier E, Constantin JM, Pelosi P, et al. Noninvasive ventilation and alveolar recruitment maneuver improve respiratory function during and after intubation of morbidly obese patients: a randomized controlled study. Anesthesiology. 2011;114(6):1354-1363.

18. Thille AW, Rodriguez P, Cabello B, Lellouche F, Brochard L. Patient-ventilator asynchrony during assisted mechanical ventilation. Intensive Care Med. 2006;32(10):1515-1522.

19. Chanques G, Constantin JM, Sauter M, et al. Discomfort associated with underhumidified high-flow oxygen therapy in critically ill patients. Intensive Care Med. 2009;35(6): 996-1003.

20. Kwiatkowski F, Girard M, Hacene K, Berlie J. Sem: a suitable statistical software adaptated for research in oncology [in French]. Bull Cancer. 2000;87(10):715-721.

21. Moerer O, Beck J, Brander L, et al. Subject-ventilator synchrony during neural versus pneumatically triggered non-invasive helmet ventilation. Intensive Care Med. 2008;34(9):1615-1623.

22. Cammarota G, Olivieri C, Costa R, et al. Noninvasive ventilation through a helmet in postextubation hypoxemic patients: 
physiologic comparison between neurally adjusted ventilatory assist and pressure support ventilation. Intensive Care Med. 2011;37(12):1943-1950.

23. Navalesi P, Costa R, Ceriana $P$, et al. Non-invasive ventilation in chronic obstructive pulmonary disease patients: helmet versus facial mask. Intensive Care Med. 2007;33(1):74-81.

24. Vargas F, Thille A, Lyazidi A, Campo FR, Brochard L. Helmet with specific settings versus facemask for noninvasive ventilation. Crit Care Med. 2009;37(6):1921-1928.

25. Leung P, Jubran A, Tobin MJ. Comparison of assisted ventilator modes on triggering, patient effort, and dyspnea. Am J Respir Crit Care Med. 1997;155(6):1940-1948.

26. Thille AW, Cabello B, Galia F, Lyazidi A, Brochard L. Reduction of patient-ventilator asynchrony by reducing tidal volume during pressure-support ventilation. Intensive Care Med. 2008;34(8):1477-1486.

27. Vignaux L, Tassaux D, Jolliet P. Performance of noninvasive ventilation modes on ICU ventilators during pressure support: a bench model study. Intensive Care Med. 2007;33(8):1444-1451.

28. Yamada Y, Du HL. Analysis of the mechanisms of expiratory asynchrony in pressure support ventilation: a mathematical approach. J Appl Physiol. 2000;88(6):2143-2150.

29. Futier E, Constantin JM, Combaret L, et al. Pressure support ventilation attenuates ventilator-induced protein modifications in the diaphragm. Crit Care. 2008;12(5):R116.
30. Jaber S, Petrof BJ, Jung B, et al. Rapidly progressive diaphragmatic weakness and injury during mechanical ventilation in humans. Am J Respir Crit Care Med. 2011;183(3):364-371.

31. Beck J, Gottfried SB, Navalesi P, et al. Electrical activity of the diaphragm during pressure support ventilation in acute respiratory failure. Am J Respir Crit Care Med. 2001;164(3): 419-424.

32. Chandra D, Stamm JA, Taylor B, et al. Outcomes of noninvasive ventilation for acute exacerbations of chronic obstructive pulmonary disease in the United States, 1998-2008. Am J Respir Crit Care Med. 2012;185(2):152-159.

33. Jaber S, Delay JM, Chanques G, et al. Outcomes of patients with acute respiratory failure after abdominal surgery treated with noninvasive positive pressure ventilation. Chest. 2005; 128(4):2688-2695.

34. Brander L, Leong-Poi H, Beck J, et al. Titration and implementation of neurally adjusted ventilatory assist in critically ill patients. Chest. 2009;135(3):695-703.

35. Rozé H, Lafrikh A, Perrier V, et al. Daily titration of neurally adjusted ventilatory assist using the diaphragm electrical activity. Intensive Care Med. 2011;37(7):1087-1094.

36. Tassaux D, Gainnier M, Battisti A, Jolliet P. Impact of expiratory trigger setting on delayed cycling and inspiratory muscle workload. Am J Respir Crit Care Med. 2005;172(10): 1283-1289. 